\section{Consumo de cafeína entre gestantes e a prevalência do baixo peso ao nascer e da prematuridade: uma revisão sistemática}

\author{
Caffeine consumption during pregnancy and \\ prevalence of low birth weight and prematurity: \\ a systematic review
}

Alice Helena de Resende Nóra Pacheco 1 Nathália Silva Raposo Barreiros 1

Iná S. Santos 2

Gilberto Kac 1

\footnotetext{
${ }^{1}$ Instituto de Nutrição Josué de Castro, Universidade Federal do Rio de Janeiro, Rio de Janeiro, Brasil. 2 Faculdade de Medicina, Universidade Federal de Pelotas, Pelotas, Brasil.

Correspondência G. Kac

Departamento de Nutrição Social e Aplicada, Instituto de Nutrição Josué de Castro, Universidade Federal do Rio de Janeiro. Av. Brigadeiro Trompowski s/n, CCS - Bloco J, Rio de Janeiro, $R J$ 21941-590, Brasil. kacetal@gmail.com
}

\begin{abstract}
This article reports on a systematic review of studies on caffeine intake during pregnancy and prevalence of low birth weight and prematurity, focusing on methods to quantify intake and control for confounding. The review consisted of an article search from 1996 to 2006 in MEDLINE, LILACS, and PubMed, using the key words: "caffeine", "coffee", "low birth weight", "birth weight", "preterm", "premature", and "prematurity". Ten articles were selected. Methods used to quantify caffeine consumption were: semi-quantitative food frequency questionnaires for diet or only caffeinated products, including one self-applied questionnaire; food recall; questions on type and method of preparation; analysis of samples; and urine and plasma caffeine levels. In three studies, high caffeine consumption was associated with low birth weight and/or prematurity. Contradictions between studies may be due to difficulties in measuring caffeine consumption; assessment of different caffeine sources; variations in the mode of preparation and amount consumed; and sample size. Association between moderate caffeine consumption and fetal growth was not demonstrated, so a more precise measurement of caffeine intake is necessary.
\end{abstract}

Caffeine; Pregnancy; Low Birth Weight Infant; Prematurity
Introdução

A cafeína (1,3,7-trimetilxantina) é um alcalóide farmacologicamente ativo ${ }^{1}$ que atua como estimulante do sistema nervoso central 2 e está presente em uma grande quantidade de alimentos (cerca de 60 espécies de plantas, no mundo, contêm compostos do tipo metilxantina), como café, guaraná, refrigerantes à base de cola, cacau, chocolate, chás e também nos remédios do tipo analgésicos, medicamentos contra gripe e inibidores de apetite 1,2 .

Esse alcalóide é o estimulante mais comum atualmente, é barato e facilmente encontrado, o que contribui para seu elevado consumo. No que diz respeito às gestantes, freqüentemente, ocorre aversão aos produtos cafeinados, particularmente ao café, no primeiro trimestre de gestação, levando à interrupção ou redução do consumo de cafeína ao longo da gravidez 3,4 .

Desde os anos 70, alguns estudos têm sugerido associação entre o consumo materno de cafeína e desfechos fetais, tais como: redução do crescimento fetal, prematuridade, restrição de crescimento intra-uterino, baixo peso ao nascer, aborto espontâneo e malformações, levando à recomendação para diminuição do consumo de cafeína no período gestacional 5,6,7,8,9.

Em 1980, baseada em resultados de estudos com ratas grávidas, a Food and Drug Administration (FDA), agência reguladora de alimentos e medicamentos dos Estados Unidos, aconselhou 
as mulheres grávidas a evitarem cafeína em sua dieta; embora, naquele momento, as implicações para a saúde humana fossem desconhecidas 10 .

Desde então, mais estudos foram feitos para determinar os efeitos da cafeína no feto. Mais recentemente, a FDA aconselhou as mulheres grávidas a evitarem, sempre que possível, alimentos e drogas contendo cafeína ou, pelo menos, manterem, durante a gravidez, o consumo abaixo de $200 \mathrm{mg}$ / dia. Outros pesquisadores definem o limite de consumo para gestantes em 300mg diários 11 .

Uma vez que a prevalência de exposição à cafeína é relativamente presente durante a gestação 12 e que o baixo peso ao nascer e a prematuridade estão associados à maior morbi-mortalidade infantis, a influência da cafeína sobre o crescimento fetal é vista como uma importante questão de Saúde Pública 4 .

Assim, esta revisão tem como objetivo investigar estudos sobre o consumo de cafeína em gestantes e seus possíveis efeitos na ocorrência de baixo peso ao nascer e na prematuridade. Serão discutidas questões metodológicas sobre quantificação do consumo de cafeína e influência das potenciais variáveis de confundimento.

\section{Métodos}

O método adotado foi o de revisão sistemática da literatura, consistindo na busca retrospectiva de artigos científicos, neste caso, sobre a associação entre o consumo de cafeína na gestação e os desfechos: baixo peso ao nascer e prematuridade. Para tal, foram utilizadas as bases de dados bibliográficos MEDLINE e LILACS (http:/ / bases.bvs.br, acessado em 11/Nov/2005) e PubMed (http://www.pubmed.com, acessado em 06/Dez/2005) e selecionados apenas os estudos publicados no período de janeiro de 1996 a janeiro de 2006.

O período escolhido para as publicações nesta revisão foi limitado em dez anos pelo fato de já existirem revisões 13,14,15,16,17 abrangendo períodos maiores de tempo: 1966 a 1995, 1974 a 1996, 1966 a 2000, 1974 a 2001 e 1977 a 2003. Assim, optou-se por incluir apenas os artigos mais recentes sobre o tema.

$\mathrm{Na}$ estratégia de busca foram utilizadas as seguintes palavras-chave: "caffeine" and "coffee" para definir a exposição, "low birth weight”, "birth weight", "preterm", "premature" and "prematurity" para os desfechos. Outra estratégia foi a busca manual em listas de referências dos artigos identificados e selecionados pela busca eletrônica.

Foram considerados critérios de inclusão os estudos com desenhos do tipo coorte, caso-con- trole e transversal que tenham sido publicados em português, inglês ou espanhol, sendo excluídos estudos nos demais idiomas.

A busca bibliográfica, segundo a estratégia estabelecida, resultou em 1.728 artigos, sendo 1.067 na base PubMed e 661 nas bases MEDLINE e LILACS. Desses artigos, 113 abordavam especificamente o tema e o período em questão; no entanto, foram excluídos: as revisões de literatura (5), os estudos repetidos nas diferentes bases de dados (70), os repetidos quando as palavraschave foram variadas (25), e os que não foram encontrados na íntegra (3). Ao final, foram selecionados dez artigos para esta revisão.

Os estudos selecionados foram avaliados em relação aos seguintes aspectos: país de origem, idioma, tipo de desenho, duração do estudo, idade média das participantes, tamanho da amostra analisada e perdas; posteriormente, fontes de cafeína incluídas no estudo, consumo médio referido ou medido, métodos adotados para quantificar tal consumo, quantidade de cafeína considerada de risco e quantidade nas fontes avaliadas; e finalmente, período da gestação em que o consumo foi avaliado, número de vezes que tal consumo foi medido, os desfechos abordados, os principais resultados, os estimadores adotados e as variáveis de confundimento controladas na análise.

Segundo diversos autores 4,16,18,19,20, a relação do consumo de cafeína com os desfechos abordados sofre influência do emprego de metodologias de baixa qualidade, as quais, por não conseguirem quantificar o consumo ideal da substância, geram resultados pouco confiáveis. Destarte, o enfoque principal do presente estudo foi no modo de medir o consumo de cafeína, bem como nos confundimentos que poderiam influenciar os resultados finais.

Os artigos selecionados foram avaliados e pontuados conforme os critérios metodológicos propostos por Downs \& Black 21, aplicáveis ao delineamento dos artigos para avaliação da qualidade dos mesmos. Tais critérios avaliam a qualidade da informação, a validade interna (vieses e confundimentos), o poder do estudo e também a validade externa. É composto, originalmente, por 31 itens; no entanto, utilizou-se, no presente artigo, a versão composta por 27 itens, da qual, os itens relacionados a estudos experimentais foram excluídos. Assim, ao final, foram avaliados 19 itens, pontuando, no máximo, 20 pontos.

Os artigos foram avaliados quanto aos seguintes aspectos: (1) hipóteses ou objetivos; (2) principais desfechos; (3) características dos pacientes incluídos; (4) distribuição das principais variáveis de confusão em cada grupo de sujeitos a ser comparado; (5) principais achados; (6) in- 
formação sobre estimativas da variabilidade aleatória nos dados para os principais desfechos; (7) informação sobre características das perdas; (8) informação sobre valores de probabilidade para os principais desfechos; (9) representatividade dosindivíduos convidados a participar do estudo; (10) representatividade dos indivíduos incluídos no estudo; (11) caso os resultados não tenham sido baseados em hipóteses estabelecidas a priori, se isto foi deixado claro; (12) se, em ensaios clínicos e estudos de coorte, a análise ajustou para diferentes durações de acompanhamento, ou, se em estudos de casos e controles o tempo entre a intervenção e o desfecho foi o mesmo para casos e controles; (13) se os testes estatísticos utilizados para medir os principais desfechos foram apropriados; (14) se as medidas utilizadas para os principais desfechos foram acuradas; (15) se os pacientes em diferentes grupos foram recrutados na mesma população; (16) se os pacientes nos diferentes grupos foram recrutados no mesmo período de tempo; (17) se a análise incluiu ajuste adequado para as principais variáveis de confusão; (18) se foram consideradas as perdas de pacientes durante o acompanhamento; (19) se o estudo tinha poder suficiente para detectar um efeito importante, com um nível de significância de $5 \%$.

\section{Resultados}

As revisões anteriormente conduzidas apresentaram conclusões divergentes. Santos et al. 13 realizaram uma meta-análise (1966 a 1995) evidenciando inconsistência quantitativa dos estudos na estimativa do efeito do consumo de cafeína sobre o peso ao nascer e a idade gestacional. Fernandes et al. 14 fizeram também uma metaanálise (1974 a 1996) e observaram aumento, estatisticamente significativo, nos riscos de aborto espontâneo e de baixo peso ao nascer entre gestantes que consumiam mais que $150 \mathrm{mg} /$ dia de cafeína.

Em 2002, Santos 15 investigou estudos de 1966 a 2000 que sugeriram um possível efeito da cafeína sobre o baixo peso ao nascer, enquanto a idade gestacional não foi associada. Tal efeito, na maioria dos estudos que compuseram a revisão, foi estatisticamente significativo. No mesmo ano, Leviton \& Cowan 16 publicaram uma revisão (1974 a 2001) concluindo não haver evidência convincente de que o consumo de cafeína aumentasse o risco de baixo peso ao nascer, prematuridade, aborto espontâneo e anomalias congênitas.

Por fim, Souza \& Sichieri 17 revisaram estudos de 1977 a 2003 apontando que, apesar dos achados serem inconclusivos, era fundamen- tal alertar as gestantes sobre o risco do elevado consumo de cafeína na gravidez. A despeito dos achados, todas as revisões foram unânimes em afirmar a necessidade de mais estudos que contemplem aspectos metodológicos, tais como: tamanho suficiente da amostra, aferição adequada da exposição e controle das potenciais variáveis de confusão.

Atendendo aos objetivos e aos critérios de inclusão pré-definidos, foram selecionados dez artigos para compor a presente revisão. Quanto ao idioma, dois estudos eram em língua portuguesa 22,23 e oito em língua inglesa 8,19,20,24,25,26,27,28 (dado não apresentado em tabela). Quatro artigos apresentaram desenho do tipo caso-controle, três eram transversais e três de coorte (Tabela 1 ).

Entre os dez artigos analisados, um abordou como fonte de cafeína somente o mate - erva típica da América do Sul, muito consumida no Sul e Sudeste do Brasil e produzida pela Argentina, Brasil e Paraguai 25, enquanto os dois estudos mais completos incluíram quase todas as fontes de cafeína, desde café (cafeinado e descafeinado), passando por chá, refrigerantes, mate, cacau, chocolate, até medicamentos 19,26. Os métodos utilizados para quantificar o consumo desses produtos e, conseqüentemente, da cafeína foram: questionário de freqüência alimentar semiquantitativo - da dieta 23 ou apenas de produtos cafeinados 19,20,22,24,25,26,27,28, sendo um do tipo auto-aplicado 27; recordatório alimentar 8; perguntas acerca do tipo e do modo de preparo 19,20,26; análise de amostras das bebidas 19; e dosagens da cafeína urinária e plasmática 20,24 (Tabela 2).

Em relação ao consumo de cafeína na população avaliada, um artigo não o relatou 22 , enquanto cinco encontraram um consumo médio de cafeína menor que 150mg/dia 8,19,20,23,25, sendo este sempre maior entre os casos quando em estudos do tipo caso-controle. A quantidade de cafeína considerada de risco para a ocorrência dos desfechos estudados variou de $\geq 100 \mathrm{mg} /$ dia 23 a $>4.000 \mathrm{mg} /$ semana $( \pm 571 \mathrm{mg} /$ dia $) 24$, e o valor mínimo confirmado como risco foi $\geq$ $71 \mathrm{mg} /$ dia ${ }^{8}$.

Assim, para efeito de comparação, as informações sobre quantidade de cafeína nas fontes avaliadas foram padronizadas utilizando-se as seguintes medidas: $100 \mathrm{ml}$, quando líquido; e $1 \mathrm{~g} \mathrm{e}$ $30 \mathrm{~g}$, quando chocolate em pó e chocolate em barra, respectivamente. Observaram-se as seguintes variações no teor médio de cafeína para cada um dos produtos: 20 a 152,86mg/100ml para o café; 17 a $33,89 \mathrm{mg} / 100 \mathrm{ml}$ para o mate; 10 a $13,43 \mathrm{mg} /$ $100 \mathrm{ml}$ para refrigerantes e/ou bebidas à base de cola; 18,89 a 30mg/100ml para chá; 9 a 20mg/30g 
Aspectos metodológicos dos estudos sobre consumo de cafeína, baixo peso ao nascer e prematuridade (1996 a 2006).

\begin{tabular}{|c|c|c|c|c|c|c|c|}
\hline Autores & $\begin{array}{c}\text { Ano da } \\
\text { publicação }\end{array}$ & $\begin{array}{l}\text { País de } \\
\text { origem }\end{array}$ & $\begin{array}{l}\text { Desenho } \\
\text { do estudo }\end{array}$ & $\begin{array}{l}\text { Duração } \\
\text { do estudo }\end{array}$ & $\begin{array}{l}\text { Faixa etária } \\
\text { (anos) }\end{array}$ & $\begin{array}{l}\text { Amostra } \\
\text { inicial (n) }\end{array}$ & $\begin{array}{l}\text { Perdas do } \\
\text { estudo (\%) }\end{array}$ \\
\hline Chiaffarino et al. 28 & 2006 & $\begin{array}{c}\text { Itália } \\
\text { (Milão e Verona) }\end{array}$ & Caso-controle & 1989 a 1999 & $\begin{array}{c}16 \text { a } 44 \text { (casos); } \\
14 \text { a } 45 \text { (controles); } \\
\text { média: } 31\end{array}$ & $\begin{array}{c}2.468 \\
502 / 1.966\end{array}$ & $\begin{array}{c}<5 \% \\
\text { (não detalhadas) }\end{array}$ \\
\hline Souza \& Sichieri 23 & 2005 & $\begin{array}{c}\text { Brasil } \\
\text { (Rio de Janeiro) }\end{array}$ & Caso-controle & $\begin{array}{l}\text { Junho de } 2000 \\
\text { a abril de } 2001\end{array}$ & $\begin{array}{c}<18 ; 18 \text { a } 34 \\
>34\end{array}$ & $\begin{array}{c}302 \\
140 / 162\end{array}$ & $\begin{array}{c}3,9 \% \\
(1 / 11 \text { perdas })\end{array}$ \\
\hline Santos et al. 25 & 2005 & Brasil (Pelotas) & Transversal & $\begin{array}{c}\text { Janeiro a dezembro } \\
\text { de } 1993\end{array}$ & $\begin{array}{c}<20 ; 20-24 ; \\
25-29 ; 30-34 ; \geq 35\end{array}$ & 5.304 & $\begin{array}{c}2,2 \% \\
\text { (115 perdas) }\end{array}$ \\
\hline Bracken et al. 20 & 2003 & $\begin{array}{l}\text { Estados Unidos } \\
\text { (Connecticut e } \\
\text { Massachusetts) }\end{array}$ & Coorte & $\begin{array}{l}\text { Setembro de } 1996 \\
\text { a janeiro de } 2000\end{array}$ & $\begin{array}{l}\leq 24 ; 25-29 \\
30-34 ; \geq 35\end{array}$ & 3.633 & $\begin{array}{c}36,9 \% \\
(1.342 \text { perdas })\end{array}$ \\
\hline $\begin{array}{l}\text { Bicalho \& } \\
\text { Barros Filho } 22\end{array}$ & 2002 & Brasil (São Paulo) & Caso-controle & $\begin{array}{l}\text { Agosto de } 1994 \\
\text { a janeiro de } 1995\end{array}$ & $\begin{array}{c}<20 ; 20-34 \\
\geq 35\end{array}$ & $\begin{array}{c}724 \\
370 / 354\end{array}$ & $\begin{array}{c}2,21 \% \\
(16 / 0 \text { perdas })\end{array}$ \\
\hline Clausson et al. 26 & 2002 & $\begin{array}{c}\text { Suécia } \\
\text { (Condado de Upsália) }\end{array}$ & Coorte & $\begin{array}{c}\text { Janeiro de } 1996 \\
\text { a setembro de } 1998\end{array}$ & $\begin{array}{r}\leq 24 ; 25-29 \\
30-34 ; \geq 35\end{array}$ & 1.037 & $\begin{array}{c}15,8 \% \\
\text { (164 perdas) }\end{array}$ \\
\hline Eskenazi et al. 27 & 1999 & $\begin{array}{c}\text { Estados Unidos } \\
\text { (Califórnia) }\end{array}$ & Transversal & $\begin{array}{c}\text { Julho a outubro } \\
\text { de } 1992\end{array}$ & $\begin{array}{c}<20 ; 20-30 ; \\
\geq 31 ; \text { média: } 25 \pm 6\end{array}$ & 7.855 & 0 \\
\hline Santos et al. 19 & 1998 & Brasil (Pelotas) & Caso-controle & $\begin{array}{c}\text { Janeiro a novembro } \\
\text { de } 1992\end{array}$ & Não informada & $\begin{array}{c}1.205 \\
401 / 804\end{array}$ & $\begin{array}{c}1,6 \% \\
(7 / 12 \text { perdas) }\end{array}$ \\
\hline Vlajinac et al. 8 & 1997 & $\begin{array}{l}\text { lugoslávia } \\
\text { (Belgrado) }\end{array}$ & Transversal & $\begin{array}{l}\text { Junho de } 1992 \\
\text { a março de } 1993\end{array}$ & Não informada & 1.032 & $\begin{array}{c}2,03 \% \\
\text { (21 perdas) }\end{array}$ \\
\hline Cook et al. 24 & 1996 & $\begin{array}{l}\text { Inglaterra } \\
\text { (Londres) }\end{array}$ & Coorte & $\begin{array}{l}\text { Agosto de } 1982 \\
\text { a março de } 1984\end{array}$ & Não informada & 1.860 & $\begin{array}{c}7 \% \\
(136 \text { perdas) * }\end{array}$ \\
\hline
\end{tabular}

* Quando considerada a dosagem sangüínea, a amostra foi ainda mais reduzida: apenas 640 mulheres, sendo, portanto, 1.220 perdas.

para chocolate; 0,6 a $2 \mathrm{mg} / \mathrm{g}$ para chocolate em pó ou achocolatado e 50 a 100mg/comprimido no caso de medicamentos. Dois artigos não relataram quantidades de cafeína em miligramas, mas apenas volume e freqüência de consumo em xícaras ou copos 27,28 (Tabela 2).

No que diz respeito aos principais resultados e estimadores adotados, três artigos 8,24,27 encontraram associação entre consumo de cafeína e baixo peso ao nascer e/ou prematuridade. Cook et al. 24 dividiram o consumo médio por grupo de semanas, encontrando associação do consumo de cafeína medido por questionário, mas não da concentração de cafeína no sangue, com baixo peso ao nascer em fumantes. Em 1997, Vlajinac et al. 8 encontraram redução no peso ao nascer em crianças nascidas de mães não-fumantes associada a um consumo médio de cafeína $\geq 71 \mathrm{mg}$ / dia. E, os resultados de Eskenazi et al. 27 mostraram redução na média de peso ao nascer para consumo de café cafeinado e aumento para café descafeinado em gramas/xícara/semana. Também observaram um aumento do risco de parto prematuro para consumidoras de ambos os tipos de café, em comparação às consumidoras apenas do cafeinado (Tabela 3 ).

Quanto ao momento em que a exposição foi aferida, seis estudos 8,19,22,23,25,28 iniciaram a avaliação do consumo de cafeína logo após o parto até, no máximo, as primeiras 72 horas após o mesmo; tais estudos avaliaram retrospectivamente e apenas uma vez a exposição. Somente um estudo iniciou a aferição da exposição no primeiro trimestre e, depois, novamente entre a 32a e a 34a semanas de gestação 26 .

De acordo com o critério proposto por Downs \& Black 21, o escore médio atribuído aos artigos selecionados foi de 16,8 , sendo 20 pontos o valor máximo atingido e 15, o mínimo. Por esse escore, destacaram-se seis artigos: um com 20 pontos 19 , 
Fontes, consumo, método de quantificação e quantidades de cafeína nos estudos sobre consumo de cafeína, baixo peso ao nascer e prematuridade (1996 a 2006).

\begin{tabular}{|c|c|c|c|c|c|c|}
\hline Autores & $\begin{array}{c}\text { Ano da } \\
\text { publicação }\end{array}$ & $\begin{array}{c}\text { Fontes de } \\
\text { cafeína }\end{array}$ & $\begin{array}{l}\text { Consumo médio } \\
\text { de cafeína } \\
\text { na amostra }\end{array}$ & $\begin{array}{c}\text { Método de } \\
\text { quantificação do } \\
\text { consumo de cafeína }\end{array}$ & $\begin{array}{c}\text { Quantidade de } \\
\text { cafeína considerada } \\
\text { de risco }\end{array}$ & $\begin{array}{l}\text { Quantidade de } \\
\text { cafeína nas } \\
\text { fontes avaliadas }\end{array}$ \\
\hline Chiaffarino et al. 28 & 2006 & $\begin{array}{c}\text { Café, chá, } \\
\text { bebidas à base } \\
\text { de cola e café } \\
\text { descafeinado }\end{array}$ & $\begin{array}{c}50 \% \text { das mulheres } \\
\text { apresentavam } \\
\text { mediana de consumo } \\
\text { de } 1 \text { xícara de café/dia. }\end{array}$ & $\begin{array}{l}\text { Questionário com } \\
\text { média de consumo, } \\
\text { em copos e xícaras } \\
\text { por dia, e duração } \\
\text { do hábito em anos } \\
\text { antes da gravidez }\end{array}$ & Não relatada & Não relatada \\
\hline Souza \& Sichieri 23 & 2005 & $\begin{array}{l}\text { Café, chá-mate } \\
\text { e chocolate } \\
\text { em pó }\end{array}$ & $\begin{array}{c}\text { Entre os casos, } \\
\text { consumo de } 56,2 \mathrm{mg} / \text { dia } \\
\text { e, entre os controles, } \\
55 \mathrm{mg} / \text { dia }\end{array}$ & $\begin{array}{l}\text { Questionário de } \\
\text { freqüência alimentar, } \\
\text { semiquantitativo, } \\
\text { com porções } \\
\text { padronizadas e } \\
\text { composto por } 64 \text { itens }\end{array}$ & $\geq 100 \mathrm{mg} / \mathrm{dia}$ & $\begin{array}{l}\text { Cada } 50 \mathrm{ml} \text { de café }= \\
\text { 35,6mg de cafeína; } \\
\text { cada } 165 \mathrm{ml} \text { de } \\
\text { chá-mate = } 47,1 \mathrm{mg} \\
\text { de cafeína; cada } 11 \mathrm{~g} \\
\text { de chocolate em pó } \\
=6,5 \mathrm{mg} \text { de cafeína }\end{array}$ \\
\hline Santos et al. 25 & 2005 & Mate & $94,5 \mathrm{mg} / \mathrm{dia}$ & $\begin{array}{l}\text { Freqüência semanal } \\
\text { de consumo }\end{array}$ & Não relatada & $\begin{array}{c}100 \mathrm{ml} \text { de mate }= \\
17 \mathrm{mg} \text { cafeína }\end{array}$ \\
\hline Bracken et al. 20 & 2003 & $\begin{array}{l}\text { Café, chá e } \\
\text { refrigerante }\end{array}$ & $<150 \mathrm{mg} / \mathrm{dia}$ & $\begin{array}{l}\text { Freqüência, tipo, modo } \\
\text { de preparo e quantidade } \\
\text { de consumo. A média } \\
\text { do consumo a cada três } \\
\text { meses gerou o consumo } \\
\text { trimestral. Foram coletadas } \\
\text { amostras das bebidas } \\
\text { do grupo intensivamente } \\
\text { monitorado para análise } \\
\text { da quantidade de cafeína. } \\
\text { Também foi realizada } \\
\text { dosagem da cafeína urinária } \\
\text { por cromatografia gasosa }\end{array}$ & $\geq 300 \mathrm{mg} / \mathrm{dia}$ & $\begin{array}{c}1 \text { xícara de café } \\
\text { filtrado }( \pm 300 \mathrm{ml})= \\
\text { 100mg de cafeína; } \\
\text { chá (fervido por } 3 \\
\text { minutos })=42 \mathrm{mg}\end{array}$ \\
\hline $\begin{array}{l}\text { Bicalho \& } \\
\text { Barros Filho } 22\end{array}$ & 2002 & $\begin{array}{l}\text { Café, refrigerante } \\
\text { (Coca-Cola ou } \\
\text { Pepsi-Cola) e chá }\end{array}$ & Não relatado & $\begin{array}{c}\text { Freqüência e quantidade } \\
\text { de consumo }\end{array}$ & $\geq 300 \mathrm{mg} / \mathrm{dia}$ & $\begin{array}{c}1 \text { xícara de café } \\
(70 \mathrm{ml})=107 \mathrm{mg} \text { de } \\
\text { cafeína; } 1 \text { xícara de } \\
\text { chá }(180 \mathrm{ml})=34 \mathrm{mg} \\
\text { e } 1 \text { lata de Coca-Cola } \\
(350 \mathrm{ml})=47 \mathrm{mg}\end{array}$ \\
\hline Clausson et al. 26 & 2002 & $\begin{array}{l}\text { Café cafeinado e } \\
\text { descafeinado, chá, } \\
\text { cacau, chocolates, } \\
\text { refrigerantes e } \\
\text { medicamentos }\end{array}$ & $\begin{array}{c}326 \mathrm{mg} / \mathrm{dia} \\
\text { (entre fumantes); } \\
155 \mathrm{mg} / \mathrm{dia} \\
\text { (entre não-fumantes); } \\
164 \mathrm{mg} / \text { dia } \\
\text { (entre os fumantes } \\
\text { passivos) }\end{array}$ & $\begin{array}{l}\text { Questionário estruturado } \\
\text { com quantidade, preparo } \\
\text { e freqüência semanal de } \\
\text { cafeína desde } 4 \text { semanas } \\
\text { antes da DUM até a última } \\
\text { semana completada (6a a } \\
\text { 12a semanas); quantidade, } \\
\text { preparo e freqüência } \\
\text { quinzenal desde a 17ạ } \\
\text { semana até a última } \\
\text { semana completada } \\
\text { (32ạ a 34a semanas) }\end{array}$ & $\begin{array}{l}300-499 \mathrm{mg} / \mathrm{dia} \\
\mathrm{e} \geq 500 \mathrm{mg} / \mathrm{dia}\end{array}$ & $\begin{array}{l}\text { 150ml de café: filtrado } \\
=115 \mathrm{mg} \text {; fervido = } \\
90 \mathrm{mg} ; \text { instantâneo = } \\
60 \mathrm{mg} ; 150 \mathrm{ml} \text { de chá } \\
\text { natural ou saquinhos } \\
\text { de chá }=39 \mathrm{mg} \text {; chá de } \\
\text { ervas }=0 \mathrm{mg} ; 150 \mathrm{ml} \\
\text { de refrigerante }=15 \mathrm{mg} ; \\
150 \mathrm{ml} \text { cacau }=4 \mathrm{mg} ; \\
1 \mathrm{~g} \text { chocolate }=0,3 \mathrm{mg} ; \\
\text { medicamentos }= \\
50-100 \mathrm{mg} / \text { comprimido }\end{array}$ \\
\hline
\end{tabular}

(continua) 


\begin{tabular}{|c|c|c|c|c|c|c|}
\hline Autores & $\begin{array}{c}\text { Ano da } \\
\text { publicação }\end{array}$ & $\begin{array}{c}\text { Fontes de } \\
\text { cafeína }\end{array}$ & $\begin{array}{l}\text { Consumo médio } \\
\text { de cafeína } \\
\text { na amostra }\end{array}$ & $\begin{array}{c}\text { Método de } \\
\text { quantificação do } \\
\text { consumo de cafeína }\end{array}$ & $\begin{array}{c}\text { Quantidade de } \\
\text { cafeína considerada } \\
\text { de risco }\end{array}$ & $\begin{array}{c}\text { Quantidade de } \\
\text { da } \\
\text { cafeína nas } \\
\text { fontes avaliadas }\end{array}$ \\
\hline Eskenazi et al. 27 & 1999 & $\begin{array}{l}\text { Café cafeinado e } \\
\text { descafeinado, } \\
\text { chá e refrigerantes } \\
\text { à base de cola }\end{array}$ & $\begin{array}{c}\text { Em xícaras/semana: } \\
6,7 \pm 6,6 * \\
6,5 \pm 7,1^{*} \\
7,3 \pm 6,8 * * \\
5,6 \pm 5,2 * *\end{array}$ & $\begin{array}{l}\text { Questionário auto-aplicado } \\
\text { com quantidade e } \\
\text { freqüência diária } \\
\text { e semanal do } \\
\text { consumo das fontes } \\
\text { de cafeína }\end{array}$ & Não relatada & Não relatada \\
\hline Santos et al. 19 & 1998 & $\begin{array}{l}\text { Café cafeinado e } \\
\text { descafeinado, mate, } \\
\text { chá, chocolate, } \\
\text { oebidas achocolatadas, } \\
\text { refrigerantes à base de } \\
\text { cola e medicamentos }\end{array}$ & $\begin{array}{c}147,76 \mathrm{mg} / \mathrm{dia} \\
\text { (entre os casos); } \\
145,90 \mathrm{mg} / \mathrm{dia} \\
\text { (entre os controles) }\end{array}$ & $\begin{array}{l}\text { Questionário com } \\
\text { freqüência, modo de } \\
\text { preparo e quantidade } \\
\text { diária consumida em } \\
\text { cada trimestre, além } \\
\text { da análise de amostras } \\
\text { ( } 10 \% \text { das mulheres } \\
\text { entrevistadas) de café e } \\
\text { folhas de mate por } \\
\text { cromatografia líquida } \\
\text { para quantificação do teor } \\
\text { de cafeína o qual foi } \\
\text { extrapolado e calculado } \\
\text { para o restante da amostra }\end{array}$ & $\geq 300 \mathrm{mg} / \mathrm{dia}$ & $\begin{array}{l}\text { Café }(\mathrm{mg} / \mathrm{ml}): \text { forte } \\
=0,25 ; \mathrm{médio}=0,2 ; \\
\text { fraco }=0,11 . \\
\text { mate: } 17 \mathrm{mg} / 100 \mathrm{ml} ; \\
\text { café instantâneo } \\
\text { (pó): } 3 \mathrm{mg} / \mathrm{g} ; \\
\text { bebida achocolatada: } \\
4 \mathrm{mg} / 200 \mathrm{ml} ; \\
\text { chá }(\mathrm{em} 180 \mathrm{ml}): \\
\text { forte }=54 \mathrm{mg} ; \\
\text { médio }=43 \mathrm{mg} ; \\
\text { fraco }=34 \mathrm{mg} ; \\
\text { refrigerantes: } \\
20 \mathrm{mg} / 200 \mathrm{ml} ; \\
\text { barra de chocolate: } \\
20 \mathrm{mg} / 30 \mathrm{~g} ; \text { medicamentos: } \\
\text { conforme DEF }\end{array}$ \\
\hline Vlajinac et al. 8 & 1997 & $\begin{array}{l}\text { Café, chá e } \\
\text { refrigerantes à } \\
\text { base de cola }\end{array}$ & $\begin{array}{c}133,44 \pm 85,82 \\
\mathrm{mg} / \mathrm{dia} ; \text { variação: } \\
0,29 \text { a } 696 \mathrm{mg} / \text { dia }\end{array}$ & $\begin{array}{c}\text { Recordatório sobre o } \\
\text { consumo de café por dia, } \\
\text { de chá por semana e } \\
\text { de bebidas com cola por } \\
\text { mês para os três } \\
\text { trimestres gestacionais }\end{array}$ & $\begin{aligned} & 71-140 \text { e Ca } \\
\geq & 141 \mathrm{mg} / \mathrm{dia}\end{aligned}$ & $\begin{array}{l}\text { Cada } 80 \mathrm{ml} \text { de café }=70 \mathrm{mg} \\
\text { de cafeína; cada } 180 \mathrm{ml} \\
\text { de chá-mate }=61 \mathrm{mg} \text { de } \\
\text { cafeína; cada } 200 \mathrm{ml} \\
\text { de bebidas com cola } \\
=26 \mathrm{mg} \text { de cafeína }\end{array}$ \\
\hline Cook et al. 24 & 1996 & $\begin{array}{l}\text { Café, chá, cacau e } \\
\text { bebidas à base } \\
\text { de cola }\end{array}$ & $\begin{array}{l}\text { Início do estudo: } \\
2.323 \pm 1.458 \mathrm{mg} / \\
\text { semana } * \star * ; \\
\text { com } 28 \text { semanas: } \\
2.605 \pm 1.375 \mathrm{mg} / \\
\text { semana } * \star * ; \text { com } \\
36 \text { semanas: } 2.427 \pm \\
1.480 \mathrm{mg} / \text { semana }\end{array}$ & $\begin{array}{l}\text { Questionário estruturado } \\
\text { acerca do consumo } \\
\text { médio de cafeína na } \\
\text { semana anterior à } \\
\text { entrevista. E, sempre que } \\
\text { possível, dosagem de } \\
\text { cafeína no plasma } \\
\text { sangüíneo }\end{array}$ & $\begin{array}{l}571 \mathrm{mg} / \mathrm{dia} \\
\text { (> 4.000mg/ } \\
\text { semana) }\end{array}$ & $\begin{array}{l}\text { Café = 92mg/xícara; } \\
\text { chá = 70mg/xícara; } \\
\text { cacau = 5mg/xícara; } \\
\text { bebidas à base de cola } \\
\text { = 40mg/porção. Para a } \\
\text { dosagem sangüínea, } \\
\text { o limite detectável para } \\
\text { cafeína foi de } 0,01 \mu \mathrm{mg} / \mathrm{ml}\end{array}$ \\
\hline
\end{tabular}

DUM: data da última menstruação; DEF: Dicionário da Especialidades Farmacêuticas.

* Consumo médio de café descafeinado;

** Consumo médio de café cafeinado;

*** Consumo estimado para as 640 mulheres cujos dados foram coletados nos três momentos do estudo.

dois com 18 pontos cada 25,26 e três com 17 8,27,28 (Tabela 3).

Ainda segundo a avaliação pelo escore de Downs \& Black 21, nota-se a fragilidade das publicações sobre os temas nos seguintes itens avaliados: sete artigos foram incapazes de determinar o po- der do estudo; três artigos atenderam, parcialmente, as informações a respeito das variáveis de confusão, enquanto dois não descreveram a distribuição destas principais variáveis; dois artigos não informaram sobre as características das perdas, e três não especificaram os valores 
de probabilidade para os principais desfechos. Com relação à validade externa, os artigos em sua maioria foram representativos e passíveis de generalização, contudo, quatro foram incapazes de determinar a representatividade dos indivíduos convidados a participar do estudo e, cinco, a dos incluídos no estudo. Quanto à validade interna, quatro estudos foram incapazes de determinar se a análise ajustou para diferentes durações de acompanhamento ou se o tempo entre a intervenção e o desfecho foi o mesmo para casos e controles.

\section{Discussão}

Os estudos acerca do consumo de cafeína e sua influência em desfechos da saúde reprodutiva, seja esta materna ou fetal, vêm crescendo e melhorando do ponto de vista metodológico, sobretudo na última década. Contudo, esse fato não significa que resultados positivos e comprobatórios da associação entre consumo de cafeína e desfechos reprodutivos têm sido encontrados e colocado em risco a ingestão da substância. Pelo contrário, de acordo com as mais recentes pesquisas, não há razão para limitar ou mesmo interromper o consumo de cafeína durante a gestação.

Os resultados da maioria dos estudos revisados reforçam tal ponto de vista 19,20,22,23, a saber: Bracken et al. 20 afirmam que o consumo moderado de cafeína não influencia o crescimento fetal, porém destacam que grandes quantidades ( $\geq 600 \mathrm{mg}$ ) devem ser evitadas; enquanto que, para Bicalho \& Barros Filho 22, mesmo em doses acima de 300mg, a ingestão de cafeína não parece estar associada ao baixo peso ao nascer, considerando-se precipitada a diminuição do consumo da substância. Já para Souza \& Sichieri 23, a ingestão elevada de cafeína é rara e, tendo em vista o padrão de consumo que observaram, não julgaram necessário difundir o não-consumo da substância em gestantes brasileiras. Assim também, segundo achados de Santos et al. 19, a completa proibição do consumo de cafeína durante a gestação não parece recomendada.

Por outro lado, entre os três estudos 8,24,27 que mostraram associação, Cook et al. 24 consideraram recomendável que mulheres fumantes reduzissem o consumo de cafeína durante a gestação, bem como abandonassem o hábito de fumar, visto que seus achados demonstraram associação negativa da ingestão de cafeína com o peso ao nascer, possivelmente, apenas em mulheres fumantes. Contrários a esse estudo, Vlajinac et al. 8 observaram tal associação apenas em crianças nascidas de mães não-fumantes, suge- rindo que o efeito do fumo seria, provavelmente, maior que o da cafeína e, dessa forma, "anularia" o efeito desta nas mulheres fumantes. Também encontrando associação, Eskenazi et al. 27 , sugeriram que o aumento no risco de parto prematuro para consumidoras tanto do café descafeinado quanto do cafeinado era devido a outros componentes do café que não a cafeína. Cabe ressaltar que duas dessas pesquisas eram do tipo transversal 8,27, não sendo este desenho de estudo o mais apropriado para inferir causalidade.

No estudo de Souza \& Sichieri 23, o consumo foi aferido por meio de questionário de freqüência semiquantitativo previamente validado, o que minimizou importantes erros, possíveis vieses e ajustou o questionário à população investigada. Os resultados não mostraram risco de prematuridade com o consumo de cafeína. Contudo, não foram investigadas todas as fontes de cafeína e nem consideradas variações quanto ao preparo. Em estudo realizado por Santos et al. 25, analisou-se apenas o consumo de mate, bebida freqüentemente consumida na região, e tal consumo não foi associado a risco aumentado de prematuridade.

Assim, percebe-se que alguns estudos que abordam o assunto são limitados pela falta de informação acerca das várias fontes de cafeína; uns avaliam somente o café 5,29,30,31 e outros apenas o mate 25. Medir somente o consumo de café pode contribuir para a falta de resultados positivos quando a cafeína é a real exposição de interesse.

Ademais, muitos dos estudos que aplicaram questionário para quantificar o consumo de cafeína não consideraram fatores importantes, tais como: viés de memória, sobretudo quanto às informações de consumo coletadas retrospectivamente 8,19,22,23,25,28; forma de preparo; quantidade de cafeína nas fontes avaliadas, o tipo e a marca dos produtos 8,22,23,24,25,28. Além disso, um questionário foi do tipo auto-aplicado 27 , o que pôde gerar viés na estimativa de associação por falta de entendimento das questões e de precisão nas respostas pelos entrevistados.

É possível também que as diferenças encontradas entre os estudos sejam atribuídas, em parte, às variações entre as populações no preparo do café. Camargo \& Toledo ${ }^{18}$, avaliando a quantidade de cafeína nos diferentes tipos de café normalmente consumidos pela população brasileira, observaram grande variabilidade no teor da substância, conforme a quantidade de pó utilizada, o tipo de café e a forma de preparo. Bracken et al. 20 observaram variação até quando a mesma pessoa fervia o café ou o chá em condições aparentemente idênticas e no mesmo dia. 
Tabela 3

Aspectos metodológicos, resultados e escores, segundo Downs \& Black 21, dos estudos sobre consumo de cafeína, baixo peso ao nascer e prematuridade (1996 a 2006).

\begin{tabular}{|c|c|c|c|c|}
\hline Autores & $\begin{array}{c}\text { Ano da } \\
\text { publicação }\end{array}$ & $\begin{array}{l}\text { Período de avaliação } \\
\text { da exposição }\end{array}$ & $\begin{array}{l}\text { Número de vezes que } \\
\text { aferiu a exposição }\end{array}$ & $\begin{array}{l}\text { Desfechos } \\
\text { abordados }\end{array}$ \\
\hline Chiaffarino et al. 28 & 2006 & Após o parto & 1 & $\begin{array}{c}\text { Prematuridade para bebês nor } \\
\text { para idade gestacional e } \\
\text { para bebês pequenos para } \\
\text { idade gestacional }\end{array}$ \\
\hline Souza \& Sichieri 23 & 2005 & $\begin{array}{l}\text { Primeiras } 72 \text { horas } \\
\text { após o parto }\end{array}$ & 1 & Prematuridade \\
\hline Santos et al. 25 & 2005 & Logo após o parto & 1 & Prematuridade \\
\hline Bracken et al. 20 & 2003 & $\begin{array}{l}\text { Antes da 25ạ semana } \\
\text { gestacional e, } \\
\text { depois, na } 20 \underline{a}, \\
\text { na } 28 \underline{a} \text { e na } \\
\text { 36a semanas }\end{array}$ & $\begin{array}{c}2 \text { (grupo telefone); } \\
4 \text { (grupo monitorado } \\
\text { intensivamente); } \\
4 \text { (grupo monitorado } \\
\text { bioquimicamente) }\end{array}$ & $\begin{array}{c}\text { Baixo peso ao nascer } \\
\text { e prematuridade }\end{array}$ \\
\hline
\end{tabular}


Tabela 3 (continuação)

Aspectos metodológicos, resultados e escores, segundo Downs \& Black21, dos estudos sobre consumo de cafeína, baixo peso ao nascer e prematuridade (1996 a 2006)

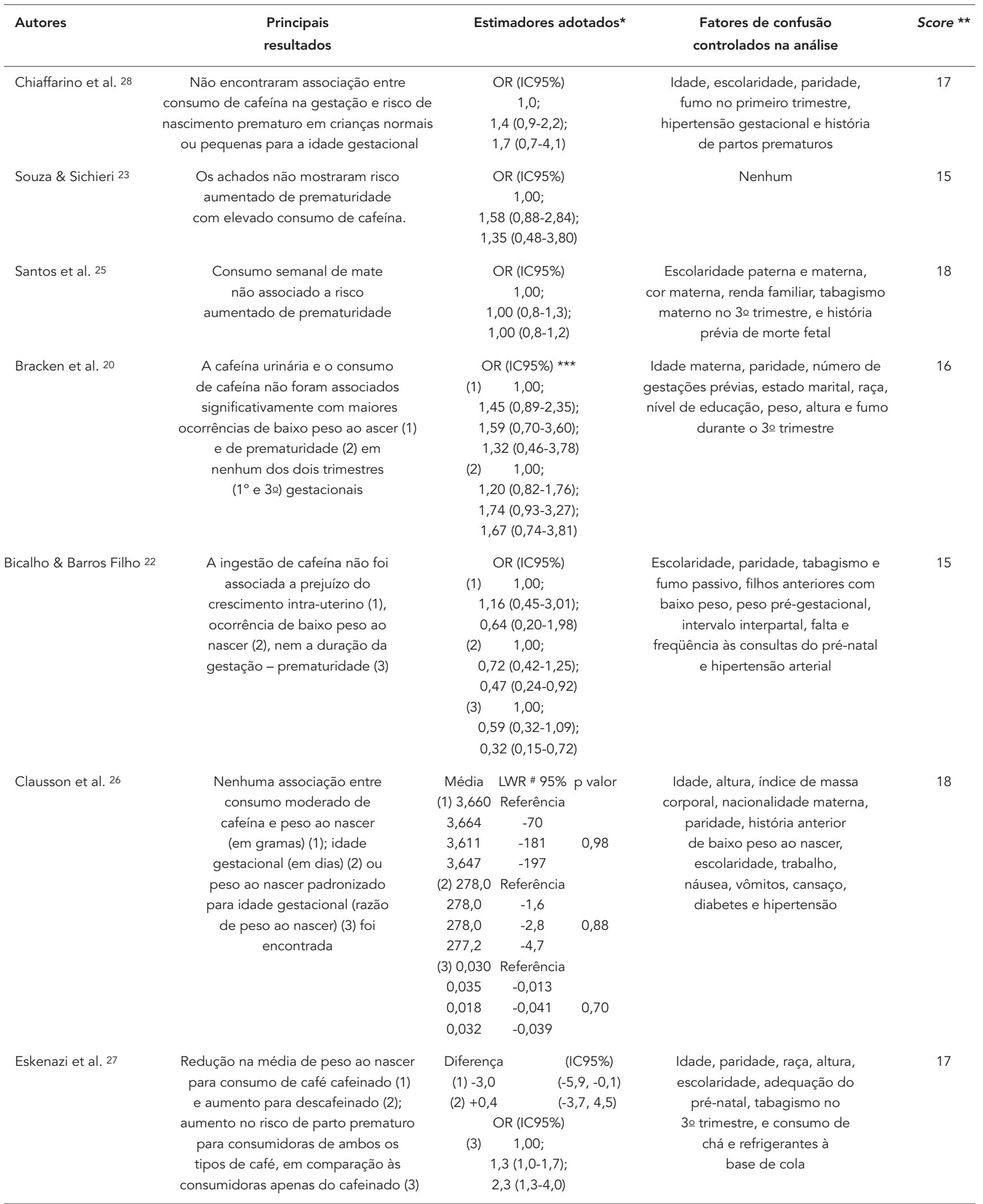

(continua) 
Tabela 3 (continuação)

Aspectos metodológicos, resultados e escores, segundo Downs \& Black 21, dos estudos sobre consumo de cafeína, baixo peso ao nascer e prematuridade (1996 a 2006).

\begin{tabular}{|c|c|c|c|c|}
\hline Autores & $\begin{array}{c}\text { Ano da } \\
\text { publicação }\end{array}$ & $\begin{array}{l}\text { Período de avaliação } \\
\text { da exposição }\end{array}$ & $\begin{array}{c}\text { Número de vezes que } \\
\text { aferiu a exposição }\end{array}$ & $\begin{array}{l}\text { Desfechos } \\
\text { abordados }\end{array}$ \\
\hline Santos et al. 19 & 1998 & $\begin{array}{l}\text { Após o parto, } \\
\text { durante o período } \\
\text { de internação } \\
\text { no hospital }\end{array}$ & $\begin{array}{c}1 \\
\text { (10\% da amostra foi } \\
\text { reentrevistada, em casa, } \\
\text { para coleta de amostras } \\
\text { de café e mate para } \\
\text { análise laboratorial) }\end{array}$ & $\begin{array}{c}\text { Peso ao nascer, duração } \\
\text { da gestação e retardo } \\
\text { de crescimento } \\
\text { intra-uterino }\end{array}$ \\
\hline Vlajinac et al. 8 & 1997 & $\begin{array}{l}\text { Durante os } \\
\text { primeiros três dias } \\
\text { após o parto }\end{array}$ & 1 & Peso ao nascer \\
\hline Cook et al. 24 & 1996 & $\begin{array}{c}\text { Com até } 24 \\
\text { semanas, com } 28 \\
\text { e com } 36 \text { semanas } \\
\text { de gestação }\end{array}$ & 3 & Peso ao nascer \\
\hline
\end{tabular}

(continua)

Os países latinos e a Itália têm tradicionalmente o hábito de tomar café mais concentrado, com maior teor de cafeína, enquanto que os americanos preferem o café bem mais diluído. Logo, é evidente a importância de saber a quantidade de cafeína nas preparações consumidas nos países de origem dos estudos e as diferenças no modo de preparo, a fim de que os resultados possam ser generalizados para outras populações.

Alguns estudos relatam que o consumo médio de cafeína permanece o mesmo durante a gestação 7,32,33; no entanto, outros consideram importante que tal ingestão seja avaliada no terceiro trimestre gestacional, visto que o consumo neste período parece ser o mais relevante para analisar a ocorrência de parto prematuro ${ }^{34}$.

A prematuridade e o baixo peso ao nascer são os fatores mais importantes na determinação da mortalidade neonatal 35 e podem ser influenciados por diversos outros fatores, dentre estes, a idade materna. Sendo assim, uma limitação metodológica de alguns desses estudos foi a inclusão de mulheres na faixa etária de risco, isto é, com idades inferior a 18 anos e maior que 35 $20,22,23,25,26,27,28$. Contudo, tal problema foi sana- do com o ajuste da análise para o efeito da idade na maioria dessas publicações 20,26,27,28.

Bicalho \& Barros Filho 22 mostraram que a ingestão de cafeína não foi associada à restrição do crescimento intra-uterino, ocorrência de baixo peso ao nascer, nem à duração da gestação e ressaltaram o problema do tamanho amostral, sobretudo a quantidade de pessoas com consumo elevado da substância, visto que menos de $19 \%$ da amostra informaram grande ingestão de cafeína (> 300mg/dia), podendo isto explicar a ausência de associação entre tal consumo e os desfechos analisados.

$\mathrm{Na}$ coorte realizada por Clausson et al. 26 , o consumo médio de cafeína foi dividido entre fumantes (326mg/dia), não-fumantes (155mg/ dia) e fumantes passivos (164mg/dia), mostrando que o consumo de cafeína é maior entre as mulheres fumantes. Vlajinac et al. 8 encontraram redução no peso ao nascer em crianças nascidas de mães não-fumantes associada a um consumo médio de cafeína $\geq 71 \mathrm{mg} /$ dia, sendo esse o estudo que encontrou associação com a menor quantidade de cafeína consumida.

Percebe-se que, na literatura, ainda há dúvidas se o consumo habitual de cafeína pode cau- 
Tabela 3 (continuação)

Aspectos metodológicos, resultados e escores, segundo Downs \& Black 21, dos estudos sobre consumo de cafeína, baixo peso ao nascer e prematuridade (1996 a 2006).

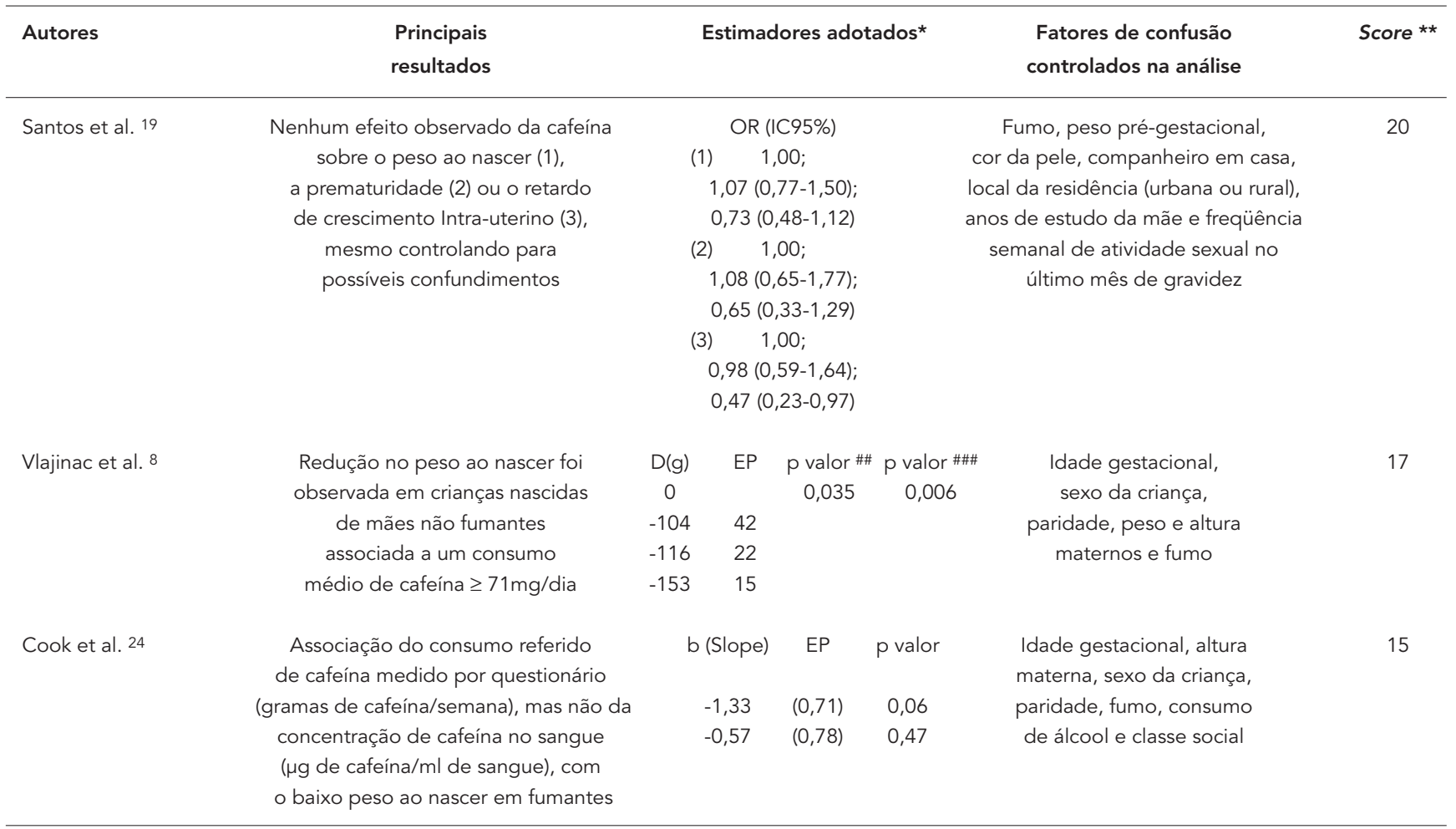

$\mathrm{D}(\mathrm{g})$ : diferença na média de peso ao nascer, em gramas; EP ou EPM: erro padrão da média; b (slope): coeficiente de regressão.

* Estimadores adotados referem-se aos principais resultados citados na tabela;

** Downs \& Black score:

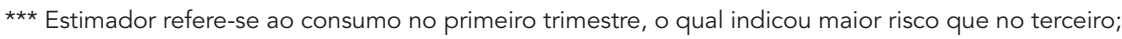

\# Limite inferior do intervalo de confiança de 95\% two-sided para a diferença no valor da média;

\#\# Across groups;

\#\#\# Tendência linear (linear trend).

sar conseqüências deletérias na reprodução humana, repercutindo em desfechos como baixo peso ao nascer e prematuridade $3,12,19,36,37,38$. O mecanismopeloqualacafeínapareceinfluenciar o crescimento fetal ainda não está definido ${ }^{39}$, e mais, não é claro se a cafeína teria efeito independente do fumo e do álcool 40 .

As razões para tais dúvidas e contradições incluem: seleção e tamanho da amostra; desenho do estudo; tempo de avaliação do consumo; ocorrências durante a gestação, tais como doenças ou outras que afetem a ingestão de cafeína; falta de um grupo de não-expostos para comparação; controle inadequado dos confundimentos, tais como o fumo e o consumo de álcool 9; e dificuldades na mensuração do consumo de cafeína por meio de questionário 23 .

Apesar de alguns estudos serem limitados do ponto de vista metodológico, outros foram bem detalhados 19,20,26, coletaram informação de medicação contendo cafeína 19,26, os confundimentos foram controlados por análise multivariada $8,19,20,22,24,25,262,7,28$ e os níveis corporais de cafeína (sangüíneo ou urinário) foram medidos 20,24. A atenção a esses critérios metodológicos rendeu aos estudos citados elevada pontuação pelo escore de Downs \& Black 21 .

Contudo, persistem limitações metodológicas na literatura disponível: a aferição detalhada e adequada da exposição, abordando todas as fontes de cafeína; o controle das variáveis de confundimento nas análises e a estimativa do poder do estudo. Logo, há a necessidade de mais estudos que se preocupem com essas limitações e tenham poder suficiente para detectar tais associações e inferir causalidade. Assim, será possível determinar se o consumo de cafeína influencia o perfeito desenvolvimento e crescimento fetais. 


\section{Resumo}

Realizou-se revisão sistemática sobre o consumo de cafeína em gestantes na ocorrência de baixo peso ao nascer e prematuridade, enfocando métodos para quantificação deste consumo e confundimentos controlados na análise. A revisão consistiu na busca de artigos publicados de 1996 a 2006 nas bases MEDLINE, LILACS e PubMed, utilizando-se as palavras-chave: "caffeine", "coffee", "low birth weight", "birth weight", "preterm", "premature" e "prematurity". Dez artigos foram selecionados. Os métodos utilizados para quantificar o consumo de cafeína foram: questionário de freqüência alimentar semiquantitativo - da dieta ou apenas de produtos cafeinados, sendo um do tipo auto-aplicado; recordatório alimentar; perguntas sobre tipo e modo de preparo; análise de amostras; e dosagens urinária e plasmática. Em três estudos revisados, o consumo elevado de cafeína associou-se com baixo peso ao nascer elou prematuridade. Contradições nos achados devemse a dificuldades na mensuração do consumo de cafeina; às fontes abordadas; a variações no preparo e na quantidade consumida; e ao tamanho amostral. Não foi demonstrada associação entre ingestão moderada de cafeína e crescimento fetal, sendo necessária uma avaliação mais precisa do consumo dessa substância.

Cafeína; Gravidez; Recém-Nascido de Baixo Peso; Prematuridade

\section{Referências}

1. International Agency for Research on Cancer. Coffee, tea, maté, methylxanthines and methylglyoxal. Lyon: International Agency for Research on Cancer; 1991. (IARC Monographs on the Evaluation of Carcinogenic Risks to Humans, 51).

2. Rang HP, Dale MM. Farmacologia. 2a Ed. Rio de Janeiro: Editora Guanabara Koogan; 1993.

3. Lawson CC, LeMasters GK, Wilson KA. Changes in caffeine consumption as a signal of pregnancy. Reprod Toxicol 2004; 18:625-33.

4. Grosso LM, Bracken MB. Caffeine metabolism, genetics, and perinatal outcomes: a review of exposure assessment considerations during pregnancy. Ann Epidemiol 2005; 15:460-6.

5. Mau G, Netter P. Are coffee and alcohol consumption risk factors in pregnancy? Geburtsh Frauenheilk 1974; 34:1018-22.

6. van den Berg BJ. Epidemiologic observations of prematurity: effects of tobacco, coffee and alcohol. In: Reed DM, Stanley FJ, editors. The epidemiology of prematurity. Baltimore: Urban \& Schwarzenberg; 1977. p. 157-76.

7. Watkinson B, Fried PA. Maternal caffeine use before, during and after pregnancy and effects upon offspring. Neurobehav Toxicol Teratol 1985; 7:9-17.

\section{Colaboradores}

A. H. R. N. Pacheco participou de todas as etapas do estudo, desde o planejamento, levantamento bibliográfico, pontuação pelo escore Downs \& Black, análise dos resultados e elaboração final do artigo. N. S. R. Barreiros contribuiu no levantamento bibliográfico, pontuação pelo escore Downs \& Black e análise dos resultados. I. S. Santos colaborou na revisão metodológica e na revisão final do artigo. G. Kac participou do planejamento, orientação e revisão do artigo.

\section{Agradecimentos}

Conselho Nacional de Desenvolvimento Científico e Tecnológico (CNPq) e Coordenação de Aperfeiçoamento de Pessoal de Nível Superior (CAPES).
8. Vlajinac H, Petrovic RR, Marinkovic JM, Sipetic SB, Adanja BJ. Effect of caffeine intake during pregnancy on birth weight. Am J Epidemiol 1997; 145:335-8.

9. Vik T, Bakketeig LS, Trygg KU, Lund-Larsen KL, Jacobsen G. High caffeine consumption in the third trimester of pregnancy: gender-specific effects on fetal growth. Paediatr Perinat Epidemiol 2003; 17:324-31.

10. Goyan JE. Food and Drug Administration news release number P80-36. Washington DC: Food and Drug Administration; 1980.

11. Food and Drug Administration. Center for Science and Public Interest Publisher of Nutrition Action Health letter. http://www.fda.gov/OHRMS/ DOCKETS/dailys/02/Apr02/042902/97p0329let6. pdf (acessado em 11/Jan/2007).

12. Lawson CC, LeMasters GK, Levin LS, Liu JH. Pregnancy hormone metabolite patterns, pregnancy symptoms, and coffee consumption. Am J Epidemiol 2002; 156:428-37.

13. Santos IS, Victora CG, Huttly S, Morris S. Caffeine intake and pregnancy outcomes: a meta-analytic review. Cad Saúde Pública 1998; 14:523-30. 
14. Fernandes O, Sabharwal M, Smiley T, Pastuszak A, Koren G, Einarson T. Moderate to heavy caffeine consumption during pregnancy and relationship to spontaneous abortion and abnormal fetal growth: a meta-analysis. Reprod Toxicol 1998; 12:435-44.

15. Santos IS. Effect of maternal caffeine consumption on birth weight and duration of pregnancy: what is the evidence? Pharmacopsychoecologia 2002; 15:163-77.

16. Leviton A, Cowan L. A review of the literature relating caffeine consumption by women to their risk of reproductive hazards. Food Chem Toxicol 2002; 40:1271-310.

17. Souza RAG, Sichieri R. Consumo de cafeína e prematuridade. Rev Nutr 2005; 18:643-50.

18. Camargo MCR, Toledo MCF. Teor de cafeína em cafés brasileiros. Ciênc Tecnol Aliment 1998; 18:421-4.

19. Santos IS, Victora CG, Huttly S, Carvalhal JB. Caffeine intake and low birth weight: a populationbased case-control study. Am J Epidemiol 1998; 147:620-7.

20. Bracken MB, Triche EW, Belanger K, Hellenbrand $\mathrm{K}$, Leaderer BP. Association of maternal caffeine consumption with decrements in fetal growth. Am J Epidemiol 2003; 157:456-66.

21. Downs SH, Black N. The feasibility of creating a checklist for the assessment of the methodological quality both of randomized and non-randomized studies of health care interventions. J Epidemiol Community Health 1998; 52:377-84.

22. Bicalho GG, Barros Filho AA. Peso ao nascer e influência do consumo de cafeína. Rev Saúde Pública 2002; 36:180-7.

23. Souza RAG, Sichieri R. Caffeine intake and food sources of caffeine and prematurity: a case-control study. Cad Saúde Pública 2005; 21:1919-28.

24. Cook DG, Peacock JL, Feyerabend C, Carey IM, Jarvis MJ, Anderson HR, et al. Relation of caffeine intake and blood caffeine concentrations during pregnancy to fetal growth: prospective population based study. BMJ 1996; 313:1358-62.

25. Santos IS, Matijasevich A, Valle NCJ. Maté drinking during pregnancy and risk of preterm and small for gestational age birth. J Nutr 2005; 135:1120-3.

26. Clausson B, Granath F, Ekbom A, Lundgren S, Nordmark A, Signorello LB, et al. Effect of caffeine exposure during pregnancy on birth weight and gestational age. Am J Epidemiol 2002; 155:429-36.
27. Eskenazi B, Stapleton AL, Kharrazi M, Chee WY. Associations between maternal decaffeinated and caffeinated coffee consumption and fetal growth and gestational duration. Am J Epidemiol 1999; 10:242-9.

28. Chiaffarino F, Parazzini F, Chatenoud L, Ricci E, Tozzi L, Chiantera V, et al. Coffee drinking and risk of preterm birth. Eur J Clin Nutr 2006; 60:610-3.

29. Arnandova R, Katsulov A. Coffee and pregnancy. Akush Ginekol 1978; 17:57-61.

30. Linn S, Schoenbaum SC, Monson RR, Rosner B, Stubblefield PG, Ryan KJ. No association between coffee consumption and adverse outcomes of pregnancy. N Engl J Med 1982; 306:141-5.

31. Uchimura TT, Szarfarc SC, Uchimura NS. A influência dos fatores comportamentais maternos na ocorrência do baixo peso ao nascer. Acta Sci 2001; 23:745-51.

32. Fortier I, Marcoux S, Beaulac-Baillargeon L. Relation of caffeine intake during pregnancy to intrauterine growth retardation and preterm birth. Am J Epidemiol 1993; 137:931-40.

33. Erkkola M, Karppinen M, Javanainen J, Rasanen L, Knip M, Virtanen SM. Validity and reproducibility of a food frequency questionnaire for pregnant Finnish women. Am J Epidemiol 2001; 154:466-76.

34. Pastore LM, Savitz DA. Case-control study of caffeinated beverages and preterm delivery. Am J Epidemiol 1995; 141:61-9.

35. Kilsztajn S, Rossbach A, Carmo MSN, Sugahara GTL. Assistência pré-natal, baixo peso e prematuridade no Estado de São Paulo. Rev Saúde Pública 2003; 37:303-10.

36. Bech BH, Nohr EA, Vaeth M, Henriksen TB, Olsen J. Coffee and fetal death: a cohort study with prospective data. Am J Epidemiol 2005; 162:983-90.

37. Tolstrup JS, Kjaer SK, Munk C, Madsen LB, Ottesen B, Bergholt T, et al. Does caffeine and alcohol intake before pregnancy predict the occurrence of spontaneous abortion? Hum Reprod 2003; 18:2704-10.

38. Dlugosz L, Bracken MB. Reproductive effects of caffeine: a review and theoretical analysis. Epidemiol Rev 1992; 14:83-100.

39. Institute of Medicine. Nutrition during pregnancy. Washington DC: National Academies Press; 1990.

40. Shu XO, Hatch MC, Mills J, Clemens J, Susser M. Maternal smoking, alcohol drinking, caffeine consumption, and fetal growth: results from a prospective study. Epidemiology 1995; 6:115-20.

\footnotetext{
Recebido em 09/Fev/2007

Versão final reapresentada em 14/Mai/2007

Aprovado em 28/Mai/2007
} 